\title{
Relationship between Dose of Bolus Dialysate Infusion and Blood Pressure in Intermittent Infusion Hemodiafiltration
}

\author{
Shigeru Otsubo ${ }^{a, b}$ Kei Eguchic Michio Mineshima ${ }^{c}$ Ken Tsuchiya $^{d}$ \\ Kosaku Nittab \\ ${ }^{a}$ Department of Blood Purification, Tohto Sangenjaya Clinic, Tokyo, Japan; ${ }^{b}$ Department of Medicine, Kidney Center, \\ Tokyo Women's Medical University, Tokyo, Japan; 'Department of Clinical Engineering, Tokyo Women's Medical \\ University, Tokyo, Japan; 'Department of Blood Purification, Kidney Center, Tokyo Women's Medical University, \\ Tokyo, Japan
}

\section{Keywords}

Bolus dialysate infusion · Intermittent back-filtrate infusion · Hemodiafiltration

\begin{abstract}
Background: Intermittent infusion hemodiafiltration is a recently developed convective method of renal replacement therapy using cyclic back-filtration infusion. Quick and regular infusion prevents intradialytic hypotension. However, the optimal dose of bolus dialysate infusion required to stabilize blood pressure has not been reported. Here, we investigated the relationship between the dose of bolus dialysate infusion and blood pressure. Summary: A total of 77 patients on maintenance hemodialysis were enrolled in this study. Dialysate was infused rapidly by backward filtration at a rate of $150 \mathrm{~mL} / \mathrm{min}$ at $30-\mathrm{min}$ intervals using an automated dialysis machine. The effects with two bolus infusion volumes (100 and $200 \mathrm{~mL}$ ) were compared, each for an observation period of 2 weeks. Systolic blood pressure (SBP) was measured at the start and at the end of each dialysis
\end{abstract}

session, and the highest SBP and lowest SBP measurements were also recorded. Patients were divided according to dry weight into a $<52 \mathrm{~kg}$ group and $\mathrm{a} \geq 52 \mathrm{~kg}$ group, and various parameters were compared between the 100 and $200 \mathrm{~mL}$ bolus infusion volumes in each group. Among patients in the $<52 \mathrm{~kg}$ group, SBP did not vary at any of the time points. However, for patients in the $\geq 52 \mathrm{~kg}$ group, SBP at the end of treatment was significantly lower in the $100-\mathrm{mL}$ group than in the $200-\mathrm{mL}$ group $(141 \pm 20$ vs. $144 \pm 21 \mathrm{~mm} \mathrm{Hg}, p=$ 0.041 ), and the minimum SBP was also lower in the $100-\mathrm{mL}$ group than in the $200-\mathrm{mL}$ group ( $127 \pm 17$ vs. $131 \pm 18 \mathrm{~mm}$ $\mathrm{Hg}, p=0.010)$. Key Messages: Among patients with a dry weight of $\geq 52 \mathrm{~kg}$, blood pressure was more stable when a bolus fluid volume of $200 \mathrm{~mL}$ was used, compared with a volume of $100 \mathrm{~mL}$. However, for patients with a dry weight of $<52 \mathrm{~kg}$, the significance of the difference in bolus fluid volumes disappeared. Thus, the replacement fluid volume might be better determined based on the patient's dry weight. Trial Registration: UMIN 000028145, Registered July 10, 2017.

(c) 2019 S. Karger AG, Basel

\section{KARGER}

(c) 2019 S. Karger AG, Basel

E-Mail karger@karger.com

www.karger.com/bpu
Shigeru Otsubo

Department of Blood Purification

Tohto Sangenjaya Clinic, 2-13-2 Taishido

Setagaya-ku, Tokyo 154-0004 (Japan)

E-Mail sotsubo@hb.tp1.jp 


\section{Introduction}

In 2013, Mineshima and Eguchi [1] developed a convective hemodiafiltration method for renal replacement therapy using cyclic back-filtration infusion and named it intermittent infusion hemodiafiltration (I-HDF). Quick and regular infusion is expected to restore blood volume, blood pressure, and peripheral circulation. Additionally, a backwash prevents hemodiafilter membrane fouling, mainly caused by low-molecular weight proteins $[1,2]$. Recently, Koda et al. [3] reported that I-HDF reduced the need for interventions for intradialytic hypotension, compared with conventional hemodialysis (HD), and was accompanied by increased intradialytic blood pressure. However, the optimal dose of bolus dialysate infusion required to stabilize blood pressure has not been reported. Here, we investigated the relationship between the dose of bolus dialysate infusion and blood pressure.

\section{Materials and Methods}

A total of 77 patients receiving maintenance HD were enrolled in this study. Dialysate was infused rapidly by backward filtration at a rate of $150 \mathrm{~mL} / \mathrm{min}$ at 30 -min intervals using a programmable system for an automated dialysis machine (TR3000 MA; Toray Medical Ltd., Tokyo, Japan). The initial infusion volume was $200 \mathrm{~mL} / \mathrm{min}$ and was then switched to $100 \mathrm{~mL} / \mathrm{min}$, and these 2 bolus infusion volumes were compared. The same hemodiafilter was used during each session. Each observation period was 2 weeks. To estimate the number of medical interventions and extent of nursing care required for patients who develop hypotension, records were kept of the total number of interventions for intradialytic reductions in blood pressure (including infusions of ultrapure dialysis fluid, $10 \%$ sodium chloride, or $50 \%$ glucose solution; elevation of the lower limbs; reduction of the blood flow rate or filtration flow rate; oxygen administration; and administration of a vasopressor agent). Blood pressure and pulse rate (PR) were measured at least every hour, and readings were recorded at baseline (at the start of each dialysis session), at the highest systolic blood pressure (SBP), at the lowest SBP, and at the end of each dialysis session and the values were averaged. A peripheral blood sample was obtained before and after the first I-HDF session of the week. Ejection fraction was obtained from the medical records. Previously, Mineshima and Eguchi [1] set the volume of each infusion not to exceed $5 \%$ of change in the patient's initial circulatory blood volume. The body weight of patients in whom $5 \%$ of the circulatory blood volume corresponds to $200 \mathrm{~mL}$ is approximately $52 \mathrm{~kg}$, and therefore, we divided patients according to dry weight into a $<52 \mathrm{~kg}$ group and a $\geq 52 \mathrm{~kg}$ group. Various parameters were compared between the treatments with the 100 and $200 \mathrm{~mL}$ bolus infusion volumes in each group.

This study was conducted in accordance with the principles of the Declaration of Helsinki and was approved by the Research Ethics Committee of Sangenjaya Hospital, Tokyo (approval number:
Table 1. Background characteristics of the study participants

\begin{tabular}{lc}
\hline Characteristic & Quantity \\
\hline Gender, male/female & $59 / 18$ \\
Age, years & $67.1 \pm 14.5$ \\
Duration of HD, years & $5.7 \pm 7.0$ \\
Primary cause of ESKD & \\
$\quad$ Chronic glomerulonephritis & $16(20.8)$ \\
Diabetic nephropathy & $31(40.3)$ \\
Nephrosclerosis & $14(18.2)$ \\
Polycystic kidney disease & $4(5.2)$ \\
Unknown and others & $12(15.6)$ \\
\hline
\end{tabular}

Data are presented as the mean \pm SD or $n(\%)$.

$\mathrm{HD}$, hemodialysis; ESKD, end-stage kidney disease.

Table 2. Hemodiafilters used in this study

\begin{tabular}{lc}
\hline Hemodiafilter & Number \\
\hline TDF-13M & 6 \\
TDF-15MV & 10 \\
TDF-20MV & 28 \\
MFX-15Meco & 21 \\
MFX-21Meco & 4 \\
MFX-25Eeco & 8 \\
\hline
\end{tabular}

H2906). The study was registered with the UMIN Clinical Trials Registry (000028145). Informed consent was obtained from all participating patients.

Data are expressed as the mean $\pm \mathrm{SD}$ or median (interquartile range). Statistical differences were determined using a two-sided paired $t$ test. For nonnormally distributed variables, a two-sided Wilcoxon's signed rank test was used. The chi-square or Fisher exact probability test was used for categorical data. All statistical calculations were performed using JMP 5.1 software (SAS Institute Inc., Cary, NC, USA). $p$ values $<0.05$ were considered statistically significant.

\section{Results}

The background characteristics of the patients are shown in Table 1. There were numerous elderly patients in this study, which gave a mean age of $67.1 \pm 14.5$ years. Diabetic nephropathy was the major cause of end-stage kidney disease.

Table 2 shows the types of hemodiafilters used in this study. High-performance membranes were used for all patients. Twenty-one patients were categorized according to dry weight into the $<52 \mathrm{~kg}$ group and 56 patients into the $\geq 52 \mathrm{~kg}$ group. The background characteristics 
Table 3. Background characteristics of the dry weight $<52$ and $\geq 52 \mathrm{~kg}$ groups

\begin{tabular}{|c|c|c|c|}
\hline & $<52 \mathrm{~kg}$ & $\geq 52 \mathrm{~kg}$ & $p$ value \\
\hline Gender, male/female & $9 / 12$ & $50 / 6$ & $<0.0001$ \\
\hline Age, years & $77.9 \pm 9.5$ & $63.1 \pm 14.1$ & $<0.0001$ \\
\hline Duration of $\mathrm{HD}$, years & $3.4 \pm 4.2$ & $6.6 \pm 7.6$ & ns \\
\hline \multicolumn{4}{|l|}{ Primary cause of ESKD } \\
\hline Chronic glomerulonephritis & $4(19.1)$ & $12(21.4)$ & \\
\hline Diabetic nephropathy & $7(33.3)$ & $24(42.9)$ & \\
\hline Nephrosclerosis & $7(33.3)$ & $7(12.5)$ & \\
\hline Polycystic kidney disease & $0(0)$ & $4(7.1)$ & \\
\hline Unknown and others & $3(14.3)$ & $9(16.1)$ & \\
\hline Ejection fraction, $\% *$ & $65.1 \pm 12.0^{* *}$ & $59.8 \pm 11.9^{* * *}$ & ns \\
\hline Body weight, kg & $47.2 \pm 3.8$ & $67.7 \pm 10.9$ & $<0.0001$ \\
\hline Albumin, g/dL & $3.9 \pm 0.3$ & $4.0 \pm 0.3$ & ns \\
\hline Urea nitrogen, $\mathrm{mg} / \mathrm{dL}$ & $56.2 \pm 11.8$ & $62.5 \pm 13.1$ & ns \\
\hline Creatinine, $\mathrm{mg} / \mathrm{dL}$ & $7.81 \pm 1.88$ & $11.20 \pm 2.32$ & $<0.0001$ \\
\hline Sodium, mEq/L & $137 \pm 4$ & $138 \pm 3$ & ns \\
\hline Calcium, mg/dL & $8.8 \pm 0.6$ & $8.8 \pm 0.6$ & ns \\
\hline Phosphate, mg/dL & $4.6 \pm 1.3$ & $6.1 \pm 5.2$ & ns \\
\hline
\end{tabular}

of both groups are shown in Table 3. There was a higher proportion of female patients in the $<52 \mathrm{~kg}$ group than in the $\geq 52 \mathrm{~kg}$ group $(p<0.0001)$. Patients were be older in the $<52 \mathrm{~kg}$ group than in the $\geq 52 \mathrm{~kg}$ group $(77.9 \pm 9.5$ vs. $63.1 \pm 14.1$ years, $p<0.0001)$. Ejection fraction did not differ between the 2 groups (with the exclusion of 7 cases for whom data were unavailable). The serum level of creatinine was lower in the $<52 \mathrm{~kg}$ group than in the $\geq 52 \mathrm{~kg}$ group $(7.81 \pm 1.88$ vs. $11.20 \pm 2.32 \mathrm{mg} / \mathrm{dL}, p<$ 0.0001 ).

A comparison of the clinical data obtained with the use of 100- and 200-mL bolus infusion doses is shown in Table 4. Session times, blood flow rate, predialysis weight, and amount of water removed per session did not differ between the groups. The urea reduction rate tended to be lower in the $100-\mathrm{mL}$ group than in the $200-\mathrm{mL}$ group $(69.5 \pm 9.0$ vs. $70.6 \pm 9.0 \%, p=0.062)$ but not significantly overall. Also, KT/V did not differ between the groups.

In all patients, SBP at the start of the session and maximum SBP were not significantly different. SBP at the end tended to be lower, albeit not significantly, in the $100-\mathrm{mL}$ group than in the $200-\mathrm{mL}$ group (140 \pm 19 vs. $142 \pm 20$ $\mathrm{mm} \mathrm{Hg}, p=0.061$ ). Minimum SBP was significantly lower in the 100-mL group than in the 200-mL group (126 \pm 17 vs. $129 \pm 17 \mathrm{~mm} \mathrm{Hg}, p=0.034)$. PR at the start and end

Dose of Bolus Dialysate Infusion and Blood Pressure in I-HDF of the session and the minimum SBP were also not significantly different. PR at maximum SBP was significantly higher in the $100-\mathrm{mL}$ group than in the $200-\mathrm{mL}$ group (76 \pm 12 vs. $74 \pm 10$ beats $/ \mathrm{min}, p=0.006$ ). The total number of interventions for hypotension was also not significantly different.

Among patients in the $<52 \mathrm{~kg}$ group, SBP and PR did not differ at any of the time points. The total number of interventions for hypotension also did not differ significantly. In contrast, for patients in the $\geq 52 \mathrm{~kg}$ group, SBP at the end was significantly lower in the $100-\mathrm{mL}$ group than in the 200 - $\mathrm{mL}$ group ( $141 \pm 20$ vs. $144 \pm 21 \mathrm{~mm} \mathrm{Hg}$, $p=0.041)$ and minimum SBP was lower in the $100-\mathrm{mL}$ group than in the $200-\mathrm{mL}$ group $(127 \pm 17$ vs. $131 \pm 18$ $\mathrm{mm} \mathrm{Hg}, p=0.010)$. PR at maximum SBP was significantly higher in the $100-\mathrm{mL}$ group than in the $200-\mathrm{mL}$ group (77 \pm 13 vs. $74 \pm 11$ beats/min, $p=0.011$ ). The total number of interventions for hypotension was not significantly different.

\section{Discussion}

The total number of interventions for hypotension did not differ between infusion volumes of 100 and $200 \mathrm{~mL}$ in patients with a dry weight of $\geq 52 \mathrm{~kg}$ and those with a 
Table 4. Comparison of clinical data between the $100-\mathrm{mL}$ and the $200-\mathrm{mL}$ bolus infusion volume groups

\begin{tabular}{|c|c|c|c|c|c|c|c|c|c|}
\hline \multirow[t]{2}{*}{ Bolus infusion dose } & \multicolumn{3}{|c|}{ All cases $(n=77)$} & \multicolumn{3}{|c|}{ Dry weight $<52 \mathrm{~kg}(n=21)$} & \multicolumn{3}{|c|}{ Dry weight $\geq 52 \mathrm{~kg}(n=56)$} \\
\hline & $100 \mathrm{~mL}$ & $200 \mathrm{~mL}$ & $p$ value & $100 \mathrm{~mL}$ & $200 \mathrm{~mL}$ & $p$ value & $100 \mathrm{~mL}$ & $200 \mathrm{~mL}$ & $p$ value \\
\hline Session time, $\mathrm{h}$ & $3.9 \pm 0.5$ & $3.9 \pm 0.5$ & ns & $3.9 \pm 0.5$ & $3.9 \pm 0.5$ & ns & $3.9 \pm 0.5$ & $3.9 \pm 0.5$ & ns \\
\hline Blood flow rate, $\mathrm{mL} / \mathrm{min}$ & $230 \pm 40$ & $228 \pm 39$ & ns & $205 \pm 34$ & $204 \pm 33$ & ns & $239 \pm 38$ & $237 \pm 37$ & ns \\
\hline Predialysis weight, kg & $62.2 \pm 13.3$ & $62.1 \pm 13.2$ & ns & $47.3 \pm 3.9$ & $47.2 \pm 3.8$ & ns & $67.8 \pm 11.0$ & $67.7 \pm 10.9$ & ns \\
\hline Amount of water removed per session, kg & $2.6 \pm 1.1$ & $2.6 \pm 1.1$ & ns & $2.0 \pm 0.9$ & $1.9 \pm 0.9$ & ns & $2.9 \pm 1.1$ & $2.8 \pm 1.1$ & ns \\
\hline Urea reduction ratio, $\%$ & $69.5 \pm 9.0$ & $70.6 \pm 9.0$ & ns & $73.1 \pm 10.2$ & $74.2 \pm 7.9$ & ns & $68.1 \pm 8.1$ & $69.2 \pm 9.0$ & ns \\
\hline $\mathrm{KT} / \mathrm{V}$ & $1.47 \pm 0.37$ & $1.53 \pm 0.45$ & ns & $1.65 \pm 0.46$ & $1.67 \pm 0.41$ & ns & $1.41 \pm 0.32$ & $1.48 \pm 0.45$ & ns \\
\hline SBP at the start, $\mathrm{mm} \mathrm{Hg}$ & $153 \pm 19$ & $153 \pm 20$ & ns & $148 \pm 15$ & $144 \pm 13$ & ns & $156 \pm 19$ & $156 \pm 22$ & ns \\
\hline SBP at the end, $\mathrm{mm} \mathrm{Hg}$ & $140 \pm 19$ & $142 \pm 20$ & ns & $136 \pm 15$ & $136 \pm 17$ & ns & $141 \pm 20$ & $144 \pm 21$ & 0.041 \\
\hline Maximum SBP, mm Hg & $162 \pm 20$ & $162 \pm 21$ & ns & $158 \pm 19$ & $159 \pm 17$ & ns & $164 \pm 20$ & $164 \pm 22$ & ns \\
\hline Minimum SBP, mm Hg & $126 \pm 17$ & $129 \pm 17$ & 0.034 & $124 \pm 14$ & $124 \pm 12$ & ns & $127 \pm 17$ & $131 \pm 18$ & 0.010 \\
\hline $\mathrm{PR}$ at the start, beat $/ \mathrm{min}$ & $79 \pm 12$ & $78 \pm 11$ & ns & $76 \pm 9$ & $75 \pm 8$ & ns & $80 \pm 12$ & $80 \pm 12$ & ns \\
\hline PR at the end, beats/min & $72 \pm 11$ & $71 \pm 10$ & ns & $70 \pm 9$ & $70 \pm 8$ & ns & $73 \pm 12$ & $72 \pm 11$ & ns \\
\hline $\mathrm{PR}$ at maximum SBP, beats/min & $76 \pm 12$ & $74 \pm 10$ & 0.006 & $72 \pm 9$ & $71 \pm 7$ & ns & $77 \pm 13$ & $74 \pm 11$ & 0.011 \\
\hline $\mathrm{PR}$ at minimum SBP, beat/min & $71 \pm 10$ & $72 \pm 10$ & ns & $70 \pm 8$ & $70 \pm 7$ & ns & $72 \pm 11$ & $71 \pm 10$ & ns \\
\hline Total number of interventions & $0(0-3.0)$ & $0(0-2.5)$ & $n s^{*}$ & $0(0-5.5)$ & $0(0-3.5)$ & $n s^{*}$ & $0(0-2.0)$ & $0(0-2.0)$ & $\mathrm{ns}^{*}$ \\
\hline
\end{tabular}

Data are presented as the mean \pm SD or median (interquartile range).

* Two-sided Wilcoxon's signed rank test.

SBP, systolic blood pressure; PR, pulse rate; ns, not significant.

dry weight of $<52 \mathrm{~kg}$. However, for patients with a dry weight of $\geq 52 \mathrm{~kg}$, blood pressure was more stable and less tachycardia was observed when a bolus fluid volume of $200 \mathrm{~mL}$, rather than $100 \mathrm{~mL}$, was used. However, this significance disappeared for patients with a dry weight of $<52 \mathrm{~kg}$.

Mineshima and Eguchi [1] reported obtaining a significantly lower average blood volume reduction with I-HDF compared with standard HD, despite there being no difference in the total amount of water removed. Thus, I-HDF was seen to enhance the transport of water and solutes from the extravascular to the intravascular compartment. I-HDF stabilizes blood pressure not only by increasing the circulating blood volume after bolus intermittent dialysate infusion but also by increasing plasma refilling. In fact, Koda et al. [3] distinctly reported that I-HDF could serve to reduce the need for medical interventions and nursing care in some patients with intradialytic hypotension and is associated with raised intradialytic SBP. The optimal dose, interval, and rate of bolus dialysate infusion required to stabilize blood pressure, however, were not reported.

Mineshima and Eguchi [1] used a bolus of 200-300 mL of dialysate at a rate of $100 \mathrm{~mL} / \mathrm{min}$ at 30 -min intervals. Koda et al. [3] used a bolus of $200 \mathrm{~mL}$ of dialysate at a rate of $150 \mathrm{~mL} / \mathrm{min}$ at 30 -min intervals. Recently, according to a report on the 62nd Annual Meeting of the Japanese
Society for Dialysis, many facilities now refer to the use of $100-200 \mathrm{~mL}$ of dialysate at a rate of $150 \mathrm{~mL} / \mathrm{min}$, with a 15- to 30-min interval [4]. Thus, in this study, we compared a bolus of $100 \mathrm{~mL}$ and a bolus of $200 \mathrm{~mL}$ and investigated the relationship between the dose of bolus dialysate infusion and blood pressure. Our findings showed that among patients with a dry weight of $\geq 52 \mathrm{~kg}$, blood pressure was more stable and less tachycardia was observed when a bolus fluid volume of $200 \mathrm{~mL} / 30 \mathrm{~min}$ was used, compared with $100 \mathrm{~mL} / 30 \mathrm{~min}$. However, this significance disappeared for patients with a dry weight of $<52 \mathrm{~kg}$, and the reason remains unclear. Even if replacement fluid volume is same, the rate of circulatory blood volume changes tends to increase more in patients with a dry weight of $<52 \mathrm{~kg}$ than in those with a dry weight of $\geq 52 \mathrm{~kg}$. After the rapid infusion phase, the infusion volume adds to the ultrafiltration volume, so a change in the ultrafiltration rate for circulatory blood volume also increases more in patients with a dry weight of $<52 \mathrm{~kg}$ than in those with a dry weight of $\geq 52 \mathrm{~kg}$. We suspect that this may result in a decrease in blood pressure in some patients with a dry weight of $<52 \mathrm{~kg}$ when the rapid infusion volume is $200 \mathrm{~mL}$. From these findings, the replacement fluid volume might be better determined based on the patient's dry weight because in patients weighing $<52 \mathrm{~kg}$, a 200 -mL dialysate infusion may represent an excessive dose. The optimal dose of bolus dialysate infusion is as yet unclear.
Otsubo/Eguchi/Mineshima/Tsuchiya/ Nitta 
We also found that less tachycardia was observed after a bolus fluid volume of $200 \mathrm{~mL}$, compared with $100 \mathrm{~mL}$. Koda et al. [3] have previously reported that PR was significantly lower during I-HDF than during standard HD. I-HDF might stimulate the sympathetic system to a lesser degree, and so a bolus volume of $200 \mathrm{~mL}$ may be better than a volume of $100 \mathrm{~mL}$ in preventing sympathetic stimulation. Weak sympathetic stimulation should improve cardiovascular stability, prevent ischemic organ injury, and enhance solute removal through capillaries and dialysis membranes [3].

The total time for the back-filtration infusion was 4 min $40 \mathrm{~s}$ longer in the 200 - $\mathrm{mL}$ group than in the 100 $\mathrm{mL}$ group when the patients received a 4 -h I-HDF treatment at a rate of $150 \mathrm{~mL} / \mathrm{min}$ at 30 -min intervals. However, KT/V or urea reduction rate did not differ between the 100 - and the $200-\mathrm{mL}$ groups. During a back-filtration infusion session, even though the blood flow rate decreases, the removal of urea continues through diffusion. Abe et al. [5] previously reported the solute removal characteristics of hemodiafilters under back-filtration conditions and the clearance rate (filtration rate -150 vs. $0 \mathrm{~mL} / \mathrm{min}$ ) of urea was above $80 \%$, while that of 2 -microglobulin was under $40 \%$. They concluded that the solute clearance of the hemodiafilter decreases with an increase in the back-filtration rate, but for small molecules, the clearance reduction is relatively small despite back-filtration because of their higher diffusion [5]. Although we could not estimate the removal of medium- or high-molecular weight solutes, our results are, in part, consistent with their findings.

Our study has some limitations. The sample size was relatively small, and the study was performed at a single institution. Sex, age, and serum creatinine level differed significantly between the $<52 \mathrm{~kg}$ group and the $\geq 52 \mathrm{~kg}$ group. Thus, although it may be preferable to divide patients according to sex, age, and serum creatinine levels, we could not do so because of the small number of participants. Another limitation of the study is that we could not use a hematocrit monitor, so we could not estimate the time course of the blood volume and plasma refilling rate. We also could not estimate the removal of middleand high-molecular weight solutes. Even though the rate of reduction of low-molecular weight solutes was similar between the 100- and 200-mL groups, the rates for middle- or high-molecular weight solutes may differ. In addition, we could not estimate the cleared space, which also might differ between the 100- and 200-mL groups. Patients should possibly also be divided according to cardiac function, serum albumin level, degree of arterioscle- rosis, or total removal weight, but such comparisons were not possible because of the relatively small number of participants in our study.

\section{Conclusion}

Among patients with a dry weight of $\geq 52 \mathrm{~kg}$, blood pressure was more stable when a bolus fluid volume of $200 \mathrm{~mL}$, rather than $100 \mathrm{~mL}$, was used. However, this significance disappeared for patients with a dry weight of $<52 \mathrm{~kg}$. The replacement fluid volume might thus be better determined based on the patient's dry weight.

\section{Acknowledgment}

The authors thank the dialysis staff of Tohto Sangenjaya Clinic for their understanding of the clinical importance of this study and for providing high-quality data.

\section{Statement of Ethics}

This study was conducted in accordance with the principles of the Declaration of Helsinki and was approved by the Research Ethics Committee of Sangenjaya Hospital, Tokyo (approval number H2906). The study was registered with the UMIN Clinical Trials Registry (000028145). Informed consent was obtained from all participating patients.

\section{Disclosure Statement}

The authors have no conflicts of interest to declare.

\section{Funding Sources}

This research received no specific grant from any funding agency in the public, commercial, or not-for-profit sectors.

\section{Author Contributions}

S.O. planned the study, searched the literature, assessed studies, extracted data, analyzed data, and drafted the manuscript. K.E. and M.M. searched the literature, assessed studies, and assisted in manuscript preparation. K.T. and K.N. assisted in manuscript preparation. All authors read and approved the final manuscript. 


\section{References}

1 Mineshima M, Eguchi K. Development of intermittent infusion hemodiafiltration using ultrapure dialysis fluid with an automated dialysis machine. Blood Purif. 2013;35(suppl 1): 55-8.

2 Mineshima M, Eguchi K, Shishido K, Takahashi S, Kubo T, Kawaguchi H, et al. Clinical effectiveness of intermittent infusion hemodiafiltration using backfiltration of ultrapure dialysis fluid compared with predilution online hemodiafiltration. Contrib Nephrol. 2017;189:24-9.
3 Koda Y, Aoike I, Hasegawa S, Osawa Y, Nakagawa $Y$, Iwabuchi F, et al. Feasibility of intermittent back-filtrate infusion hemodiafiltration to reduce intradialytic hypotension in patients with cardiovascular instability: a pilot study. Clin Exp Nephrol. 2017 Apr;21(2): 324-32.
4 Nakamoto H, Okada K, Hasegawa H, Kobayashi $\mathrm{T}$, Itsumi $\mathrm{N}$, Inoue $\mathrm{T}$, et al. The $62 \mathrm{nd}$ Annual meeting of the Japanese Society for Dialysis Therapy. J Jpn Soc Dial Ther. 2017;50 suppl 1:455-976.

5 Abe T, Yamamoto K, Ishimori I, Eguchi K, Murakami J, Mineshima M, et al. Solute removal characteristics of hemodiafilter under back-filtration conditions. Nephrol Dial Transplant. 2014;29(suppl 3):iii461-2. 